\title{
OPTIMIZATION OF CABLE-STAYED BRIDGES WITH THREE-DIMENSIONAL MODELLING $\dagger$
}

\author{
J. H. O. Negrão and L. M. C. Simões \\ Departmento de Engenharia Civil, Faculdad Ciências e Tecnologia, Universidade de Coimbra, Portugal
}

\begin{abstract}
This paper describes an analytical sensitivity analysis and optimization implementation for cable-stayed bridge design. The finite element software is based on the Vax/VMS version of the Modulef code [1 MODULEF Reference Guide. INRIA (1992).] and was adapted to an IBM-PC compatible. The main focus of this research concerns the analytical sensitivity analysis developed on this platform. The cable-stayed bridge optimization is posed as a multiobjective optimization with goals of minimum cost of material, stresses and displacements. Cable anchor positions on the main girder and pylon and cross-sectional sizes of the structural members are dealt with as design variables. By using the maximum entropy formalism it is shown that a Pareto solution may be found indirectly by the unconstrained optimization of a scalar function. The validity and effectiveness of the proposed technique is examined by means of a three-span steel cable-stayed bridge. (C) 1997 Civil-Comp Ltd and Elsevier Science Ltd.
\end{abstract}

\section{INTRODUCTION}

Modern cable-stayed bridge construction involves the assembly of an almost unlimited variety of deck, pylon and cable elements connected together in a multitude of different ways. In order that an economical and functional design can evolve, it is necessary to carry out both static and dynamic analysis for the design loadings to ensure the structure meets the required strength and serviceability criteria. It is also necessary to determine the unstrained or fabricated geometry of the bridge elements, so that after construction they adopt the desired configuration with the designed control forces in the dead load conditions. The use of computers has become an essential feature of such structural analysis and it is therefore extremely important that the operations of data preparation, computer operation and the use of computer results are carried out in an efficient way. Cable-stayed bridges are statically indeterminate and their structural behaviour is greatly affected by the cable arrangement and stiffness distribution in the cables, deck and pylons. Some authors made parametric studies in which structural elements stiffness, anchorage positions, side-to-central span ratio, etc. were considered [2-4]. However, few attempts have been made to use optimization techniques. Some papers published in Japan by the end of the 1970s address the sizing problem either by optimality criteria or mathematical programming (sequence of linear programs). Fleury's mixed variable method has been used on a two-dimensional model to

$\dagger$ In memorian José Simões. optimize the cross-section of the cables, the equivalent thicknesses of the upper and lower flanges of the pylon and deck box girders and the cable anchor positions on the main girder and pylon [5]. A multiobjective optimization coupled with semi-analytic sensitivity analysis was developed in Ref. [6].

Most time and resources consuming tasks of structural optimization problems based on finite elements approach are those of sensitivity analysis and code interfacing between the optimization and analysis modules, if an integrated process is to be considered. Each design stage involves: (1) the analysis of an initial or trial design by finite element analysis; (2) use of sensitivity analysis and approximation concepts to formulate the performance constraints as explicit linear functions of design variables; (3) optimization by means of an efficient optimization algorithm to obtain a better solution. The new design then becomes the trial design for the next design iteration, and the process is continued until the change in design over a number of successive design stages is less than some specified tolerance. The original finite element program was the VAX/VMS-based Modulef source code, that has been adapted to an IBM-compatible environment by using Phar Lap memory extender.

Two general approaches are used for computing sensitivities: differentiation of the continuum equations followed by discretization, and the reverse approach of discretization followed by differentiation [7]. The analytic method belonging to the latter class will be used here. This procedure provides accurate first-order derivatives and requires only one FE equation system assembly, at the cost of some 
programming effort at the element routines and equation solver level.

The cost of a cable-stayed bridge will be assumed proportional to the cost of material used. The constraints consist of nodal displacements and service and erection stresses. In order to ensure the desired geometric requirements throughout the optimization process, geometry coefficients which supply information related with the mesh discretization, ratios of variation of cable spacing on deck and pylons, etc. define another set of requirements. The use of envelope functions is one approach to reduce the number of constraints handled by the optimizer and making it more efficient. Finding the optimum solution can then be posed as a multicriteria optimization problem in which all the constraints and objective function are folded in a single envelope. The entropy-based approach to solving this minimax optimization formulates the problem as the minimization of a convex function with just one control parameter. The user-specified parameter controls how close the envelope is to the original constraints and the objective function.

If a general purpose optimization package is being used, a new or adapted interface code must be written whenever a new problem is to be considered. The procedure suggested in this paper reduces the effort involved to a minimum, namely by pre-defining at code level a number of types of design variables and describing their relation with the $F E$ mesh by a dependency matrix which totally controls and defines the optimization problem. This procedure is developed in the context of three-dimensional non-linear cable-stayed bridges.

\section{ANALYSIS}

A radiating longitudinal arrangement of cables was considered in the present study, though the described methodology might be used with other models. MODULEF finitc clement open codc was chosen to analyse the structure.

The behaviour of many structures can be adequately determined by a linear analysis and indeed some aspects of cable-stayed bridge behaviour are linear. However, for some problems involving the cables and also for long or slender bridges, particularly at the construction stage, the results of a linear analysis are not satisfactory and nonlinear characteristics must be accounted for [8]. Nonlinearity is introduced because of: (a) the nonlinear axial force elongation relationship for the inclined cable stays due to the sag caused by their own weight; (b) the nonlinear axial force and bending moment deformation relationships for the towers and longitudinal girder elements under combined bending and axial forces; (c) the geometry change caused by large displacements in this type of structure under normal as well as environmental design loads; (d) nonlinear constitutive stress-strain relationships for the materials of structural elements. It is assumed that Young's modulus considered for the stays in the analysis is the secant Ernst value corresponding to the expected stress level and stress variation range. Since the stress level in the stays for service load conditions is considerably high, this value differs very little from the instantaneous Young modulus and therefore nonlinear effects due to cause (a) may be expected to be very small. Also, reason (d) was discarded from our research, once only linear elastic material behaviour was assumed for structural (and, particularly, for stays-) steel.

Consider a cable-stayed bridge in service conditions and a set of loading cases, and let $\mathbf{u}$ and $\mathbf{P}$ denote, respectively, the nodal displacement and the nodal load vector for each loading case. The problem of analysing the structure reduces to the solution of a system of nonlinear equations that, when assembled for the whole structure, can be represented in matrix form as

$$
\mathbf{K u}=-\mathbf{P}+\mathbf{R}
$$

where $\mathbf{K}$ is the stiffness matrix containing coefficients of the unknown $u_{j}$ and $\mathbf{R}$ is a column residual vector corresponding to the difference between this nonlinear analysis and the results which would be obtained by a strictly linear analysis. The solution of these equations by a suitable iterative procedure will give values for $\mathbf{u}$.

Although some authors focused their investigations on two-dimensional static nonlinear analysis of cable-stayed bridges, very few attempts have been made to solve the tridimensional problem. Bearing in mind the complex design conditions that must be considered, namely those corresponding to transversally asymmetric load conditions, as well as the perspectives of increasing spans and complex geometries, a nonlinear tridimensional analysis is a fundamental step for a reliable design [9].

\section{OPTIMIZATION}

\subsection{Cable-stayed bridge requirements}

The choice of the generic structural model among the various initial possibilities (cable-stayed or suspended bridge, multi or single span, steel, prestressed concrete or composite structure, etc.) reported in Ref. [10] are not considered here. In this work it is assumed that the generic description of the bridge is known: main and side span lengths (depending on the selected erection site, geological conditions and clearance requirements under the deck) and deck height (depending on access conditions and clearance requirements).

Structural topology is also assumed to be defined, although modifications such as cables being discarded are allowed.

It is desirable that the integrated optimization 
package meets the following requirements: (a) there must be a minimum need for the user intervention during the optimization process, except for controlling and selecting the improved solutions; (b) new goals and design variables must be easily included without changing the computer code; (c) specific features as intermediate erection-time substructures and nonlinear behaviour (namely of the stays) must be considered.

\subsection{Decision variables}

Span lengths, number of cables and material types to be used for each structural element are the preassigned constant design parameters. The 16 design variable types presently available are shown at Figs $1-5$ and are as follows:

Type 1-height of full or hollow rectangular, symmetric I or plate cross-section;

Type 2-width of full or hollow rectangular or symmetric I or cross-section;

Type 3-cross-sectional area of the cables;

Type 4-side-span cable-free length;

Type 5-side-span cable anchorage zone;

Type 6-pylon cable anchorage zone;

Type 7-mid-span cable-free length;

Type 8-central span cable anchorage zone;

Type 9-top flange width of asymmetric I cross-section;

Type 10-bottom flange width of asymmetric I cross-section;

Type 11-top flange thickness of symmetric or asymmetric I cross-section;

Type 12-bottom flange thickness of symmetric or asymmetric I cross-section;

Type 13-height of asymmetric I cross-section;

Type 14-web thickness for symmetric or asymmetric I cross-section;

Type 15-plate thickness for transverse-oriented faces of hollow cross-section;

Type 16-plate thickness for longitudinal-oriented faces of hollow cross-section.

If a structure with mechanical and/or geometrical characteristics provided by the optimized solution is to be executed, it must be guaranteed that the dimensions of the structural components and cross-sections are bounded between reasonable values. These bounds exclude the choice of inadequate cross-sections, but, if element mesh and design variable set coincide, the optimized solution will probably be too discontinuous from the cross-sectional point of view. Furthermore, if geometrical design variables are to be considered, then some control must exist on the structural geometry evolution through the process to keep desired geometric characteristics, such as a certain fixed ratio for the variation of cables spacing on deck or pylons and to avoid cable crossing from occurring. In order to control the progress towards the optimum solution, design variable types are defined and the corresponding computational procedures are programmed at the element routines level. Therefore a change of the design variable set implies no modification of the interface program between analysis and optimization. The correspondence between this variable set and the finite element mesh is initially defined through a dependency matrix

$$
\mathbf{C}_{N E \times N},
$$

whose dimensions are the number of elements of the mesh $(N E)$ and the number of design variables $N$. So, $C(i, j)=k$ means that the element $i$ is affected by design variable number $j$, which is from type $k$ ( 0 if there is no dependency of the element on that variable). The desired level of continuity or homogeneity of the solution will be controlled by assigning the same variable number (column on $\mathbf{C}$ matrix) to the same variable type at the desired set of elements (rows on $\mathbf{C}$ matrix). This method allows geometry and load derivatives for the sensitivity analysis to be performed on an element basis, simultaneously with the normal computation of stiffness matrix and right-hand sides in the structural analysis.

\subsection{Erection stresses}

Cable-stayed bridges behaviour is highly dependent on the erection system used, where a detailed reference to the erection process for correctly modelling the structure is needed. Furthermore, intermediate erection stages correspond to temporary substructures which must be able to support the expected loads during that period. Therefore, a feasible optimum design must take into account the structural behaviour during the erection stages. A simplistic approach consists of optimizing the complete structure under service condition and checking each erection stage afterwards. If some constraint violation is detected, such as excessive stresses or deflections, the optimization process is repeated, imposing now more severe bounds on those design variables which more strongly affect the violated constraints. This process is very laborious, quickly becoming too complex to deal with when the number of design variables increases.

In this paper all the intermediate structures are included in the optimization process, and the optimized solutions fulfil the erection conditions. The counterpart for this approach is the need for a bigger structural system to be analysed (with between two to four times the number of degrees of freedom of the final structure, depending on the number of erection stages being considered). This is reflected by the increase in the processing time spent to obtain the solution, and in some additional pre-processing and data entry effort.

For this kind of formulation, a discontinuous fictitious structure is modelled, each of the indepen- 


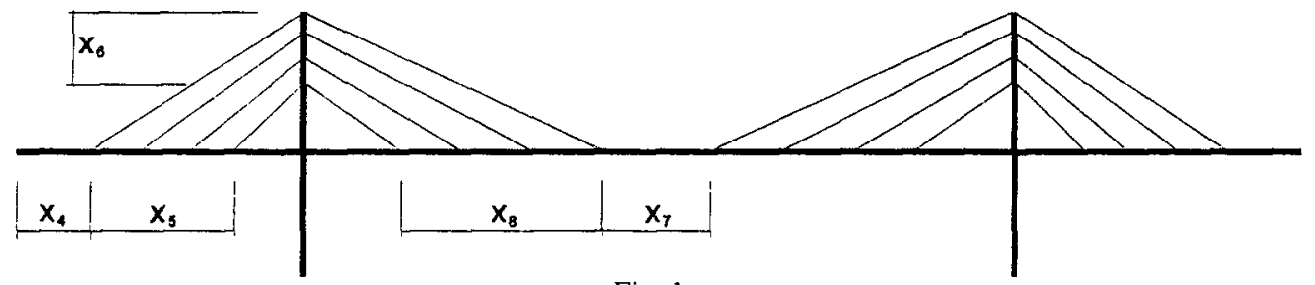

Fig. 1.

AVAILABLE MECHANIC DESIGN VARIABLE TYPES

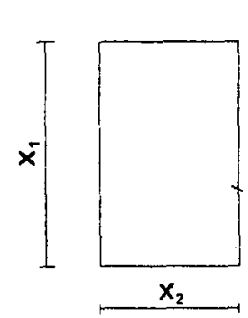

RECTANGULAR CROSS SECTION

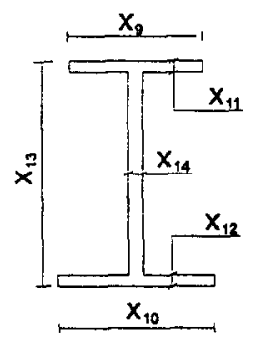

I-BEAM CROSS SECTION

Figs 2-5.
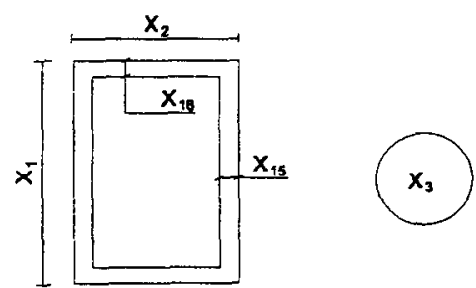

HOLLOW RECTANGLE CABLE CROSS SECTION

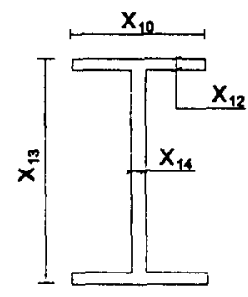

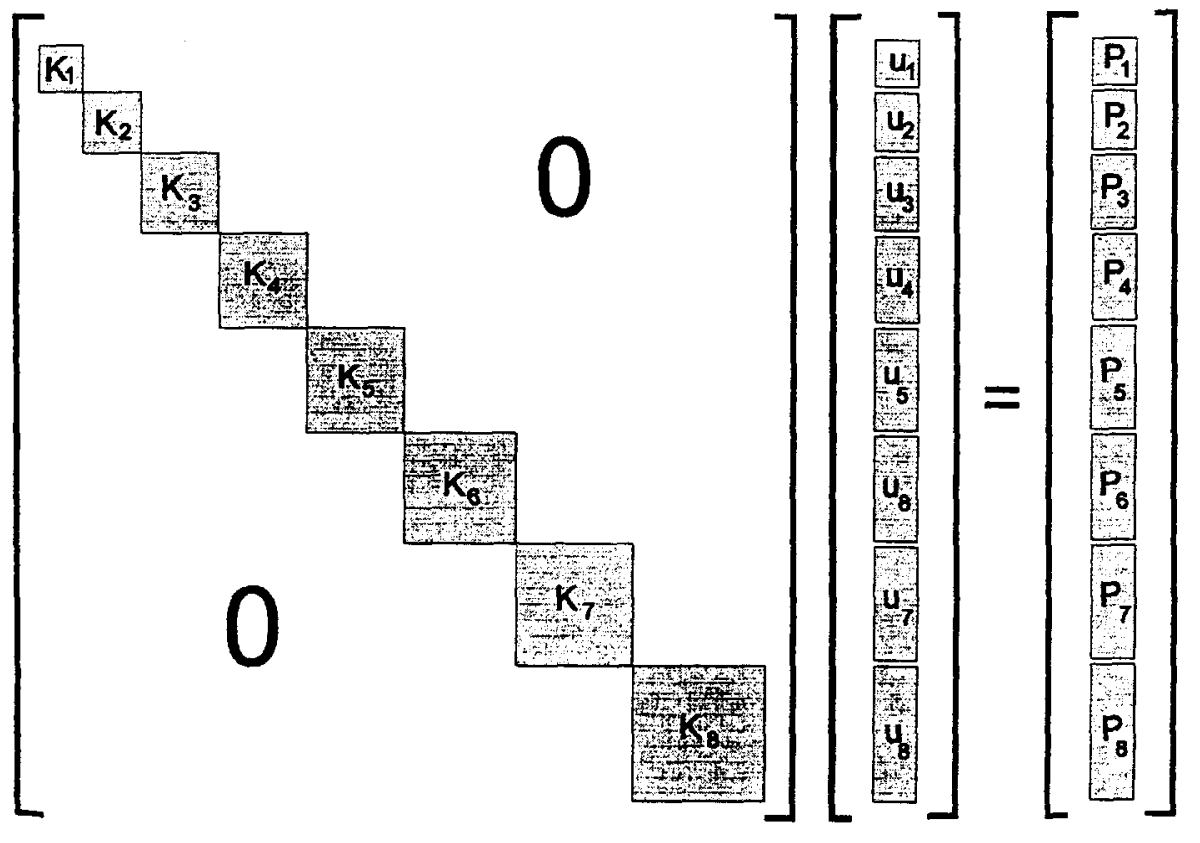

UNCOUPLED SIMULTANEOUS ANALYSIS OF FINAL AND ERECTION STAGES SUBSTRUCTURES

Fig. 6. 
" Either co-ordinate updating or complete remeshing

\section{PROGRANI BLOCK DIAGRAM}

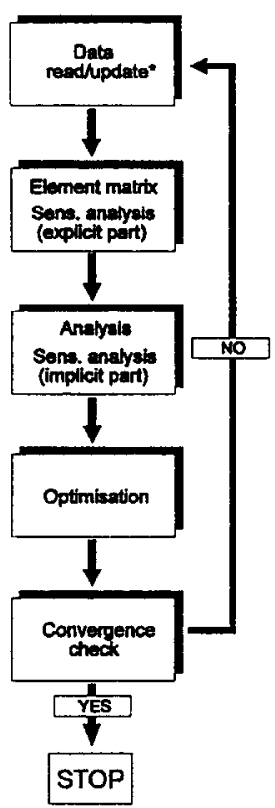

Fig. 7.

dent substructures corresponding to one of the $L$ erection stages to be considered, or to the final structure. The finite element problem so defined is composed of $L+1$ uncoupled subproblems, the simultaneous solution of which provides $L+1$ partial solutions equal to those that should be obtained by separate analysis of each substructure, as shown in Fig. 6. The advantage of this method is that final and intermediate information on the sensitivity analysis may be obtained in the same way that it would be by considering a single structure. Furthermore, and once there is no subsystem coupling, different load conditions may be assigned the same right-hand side. For example, right-hand side number

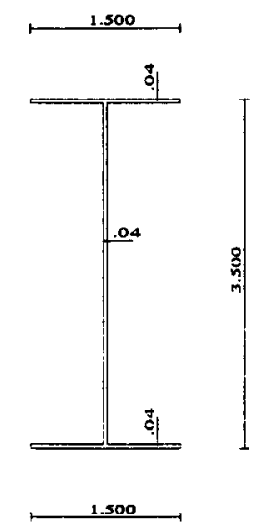

GIRDERS

(STOE SPANS)

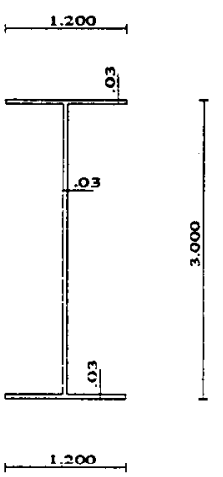

GIRDERS

(CENTRAL SPAN)

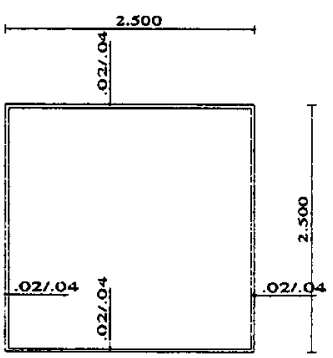

$\$$

\section{TRANSVERSE}

BEAMS

PYLONS

Fig. 9.

1 may contain the wind load for the final structure and the derrick load for the erection stages. An alternative approach to this problem, based on a substructure frontal technique, is proposed by Behin and Murray [11].

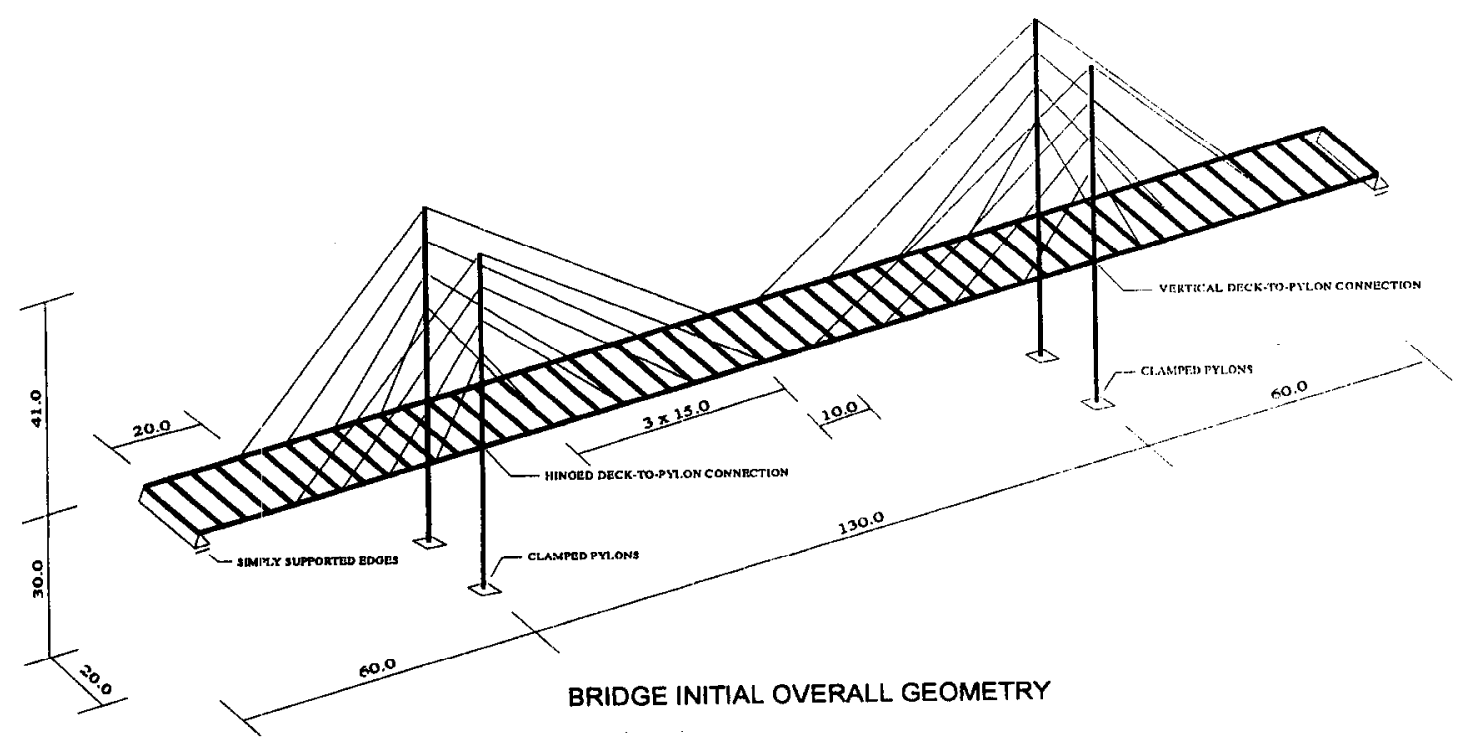

Fig. 8. 

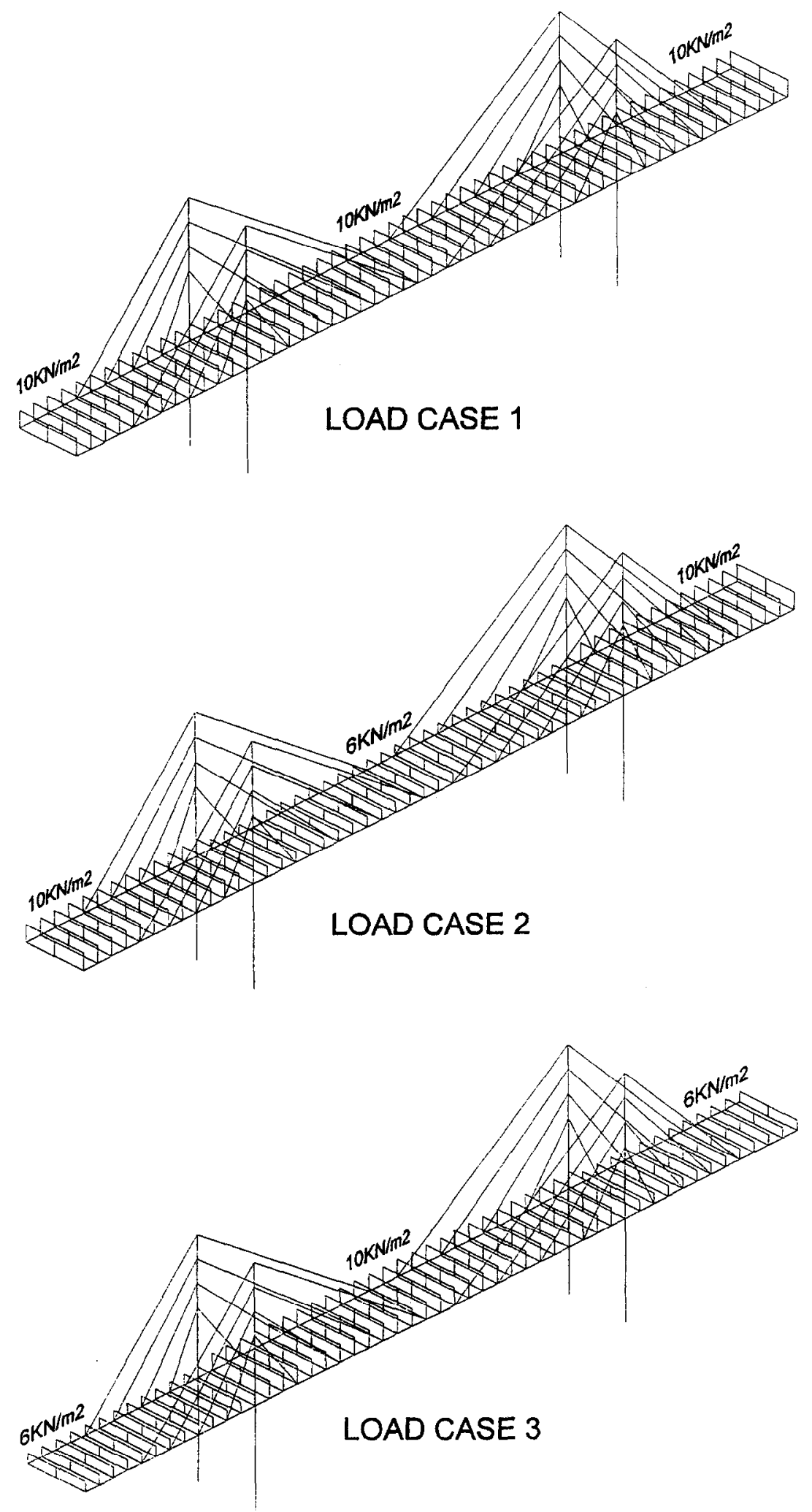

Fig. 10. 
Table 1. Design variables and their bounds

\begin{tabular}{|c|c|c|c|}
\hline$X_{\mathrm{i}}$ & Meaning & $X_{\mathrm{L}}$ & $X_{\mathrm{U}}$ \\
\hline$x_{1}$ & Side span beam upper flange width & 0.500 & 2.000 \\
\hline$x_{2}$ & Side span beam bottom flange width & 0.500 & 2.000 \\
\hline$x_{3}$ & Side span beam upper flange thickness & 0.20 & 0.05 \\
\hline$x_{4}$ & Side span beam bottom flange thickness & 0.02 & 0.05 \\
\hline$x_{5}$ & Side span beam cross-section height & 1.00 & 5.00 \\
\hline$x_{6}$ & Side span beam web thickness & 0.02 & 0.05 \\
\hline$x_{7}$ & Central span beam upper flange width & 0.50 & 1.50 \\
\hline$x_{8}$ & Central span beam bottom flange width & 0.50 & 1.50 \\
\hline$x_{9}$ & Central span beam upper flange thickness & 0.02 & 0.05 \\
\hline$x_{10}$ & Contral span bcam bottom flange thickness & 0.02 & 0.05 \\
\hline$x_{11}$ & Central span beam cross-section height & 1.00 & 4.00 \\
\hline$x_{12}$ & Central span beam web thickness & 0.02 & 0.05 \\
\hline$x_{13}$ & Pylon cross-section height (below deck level) & 1.50 & 4.00 \\
\hline$x_{14}$ & Pylon cross-section width (below deck level) & 1.50 & 4.00 \\
\hline$x_{15}$ & Pylon cross-section in-plane wall thickness (below deck level) & 0.02 & 0.10 \\
\hline$x_{16}$ & Pylon cross-section normal-to-plane wall thickness (below deck level) & 0.02 & 0.10 \\
\hline$x_{17}$ & Pylon cross-section height (above deck level) & 1.50 & 4.00 \\
\hline$x_{18}$ & Pylon cross-section width (above deck level) & 1.50 & 4.00 \\
\hline$x_{19}$ & Pylon cross-section in-plane wall thickness (above deck level) & 0.02 & 0.10 \\
\hline$x_{20}$ & Pylon cross-section normal-to-plane wall thickness (above deck level) & 0.02 & 0.10 \\
\hline$x_{21}$ & Side span cables cross-section area & $1 \mathrm{E}-8$ & 0.10 \\
\hline$x_{22}$ & Central span cables cross-section area & $1 \mathrm{E}-8$ & 0.10 \\
\hline$x_{23}$ & Transverse beams flanges width & 0.30 & 1.00 \\
\hline$x_{24}$ & Transverse beams height & 0.50 & 2.00 \\
\hline$x_{25}$ & Transverse beams flanges thickness & 0.02 & 0.05 \\
\hline$x_{26}$ & Transverse beams web thickness & 0.02 & 0.05 \\
\hline$x_{27}$ & Cable-free deck length in side spans & 1.00 & 30.00 \\
\hline$x_{28}$ & Cable zone deck length in side span & 1.00 & 50.00 \\
\hline$x_{29}$ & Cable zone pylon length & 5.00 & 50.00 \\
\hline$x_{30}$ & Cable-free deck length at midspan & 1.00 & 50.00 \\
\hline$x_{31}$ & Cable zone deck length at central span & 1.00 & 60.00 \\
\hline
\end{tabular}

\subsection{Iterative analysis}

An initial design is iteratively modified and analysed until it is acceptable. The modification element of the process consists of setting up a formal optimization model which redefines the design variable values in the way represented by the flowchart of Fig. 7. The geometry cocfficients set the rules for mesh updating to keep discretization as smooth as possible. An analytical procedure was developed for the sensitivity analysis, because it provides greater accuracy on the derivatives and a lower processing time. Alternative semi-implicit or explicit (finite differences) sensitivity analysis methods are also available.

Convergence checks can be formulated in a number of different ways. In this work a condition concerning the cost decrease within an iteration was imposed.

If one wishes to change the optimization-related data, such as the design variable set, only the dependency matrix $\mathbf{C}$ needs to be changed by adding, removing or changing some of their columns.

\subsection{Multi-objective formulation}

Pareto's economic principle is gaining increasing acceptance to multi-objective optimization problems. In minimization problems, a solution vector is said to be Pareto optinal if no other feasible vector exists that could decrease one objective function without increasing at least another one. The optimum vector usually exists in practical problems and is not unique.

Cross-sectional (and geometric) design variables are considered, represented by $x_{i}$ and $z_{i}$, respectively, and the global design variable vector is

$$
\mathbf{X}=\left\{x_{1}, x_{2}, x_{3}, \ldots, x_{n}, z_{i+1}, z_{i+2}, \ldots, z_{N}\right\}^{\mathrm{T}} .
$$

Bounds must be set for these variables in order to achieve executable solutions and required aesthetic characteristics.

The overall objective of cable-stayed bridge design is to achieve an economic, and yet safe, solution. In this study it is not intended to include all factors influencing the economics of a design. One of the factors conventionally adopted is the cost of material used. A second set of goals arises from the requirement that the stresses should be as small as possible.

The optimization method described in the next section requires that all these goals should be cast in a normalized form. If some reference cost $V_{0}$ is specified, this goal can be written in the form

$$
g_{1}(\mathbf{x}, \mathbf{z})=V(\mathbf{x}, \mathbf{z}) / V_{0}-1 \leqslant 0 .
$$

A second set of goals arises from the imposition of lower and upper limits on the sizing variables, namely minimum cable cross-sections to prevent topology 


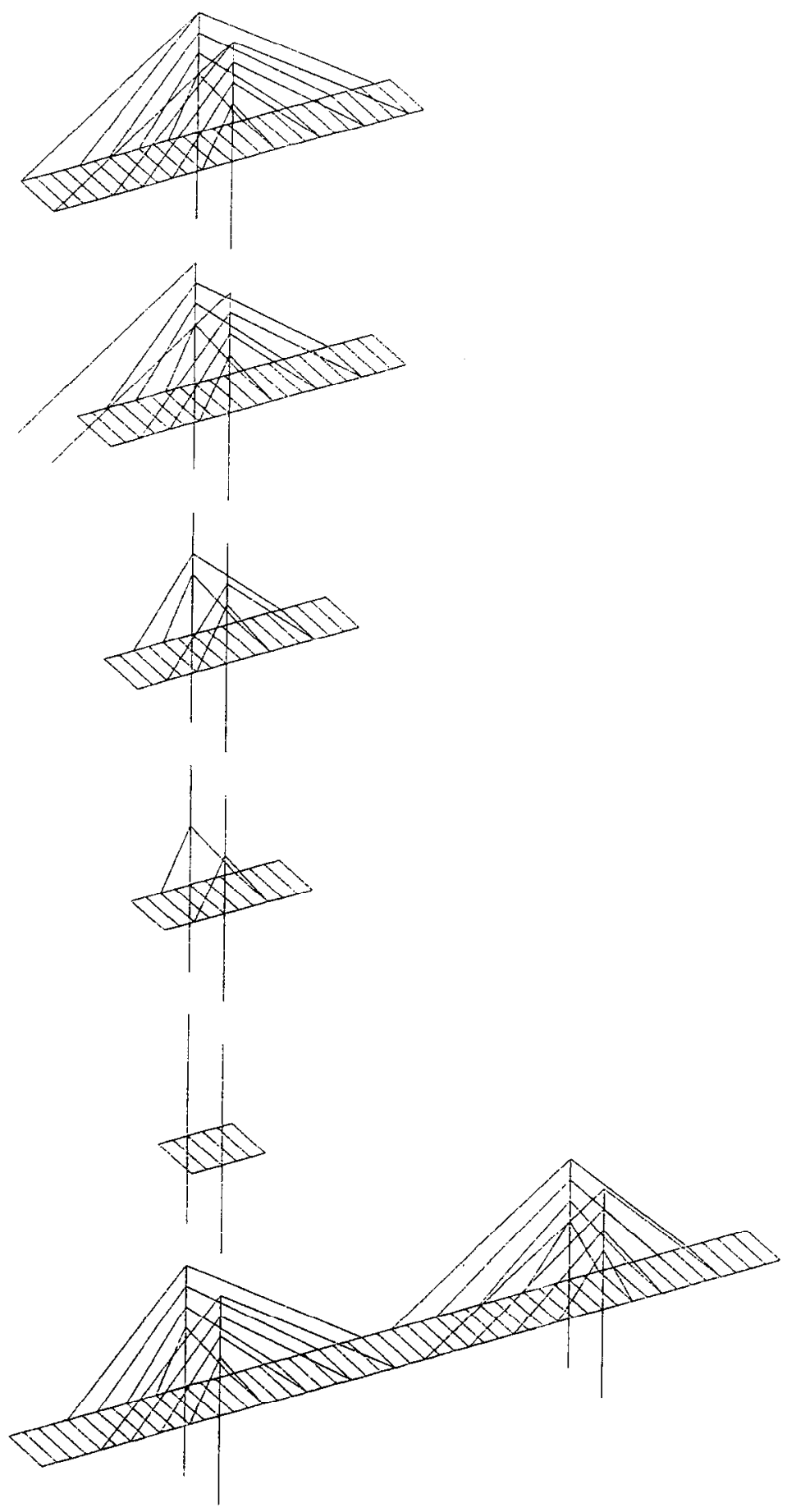

EXAMPLES 5 TO 8

FINAL STRUCTURE AND ERECTION STAGES

Fig. 11 . 


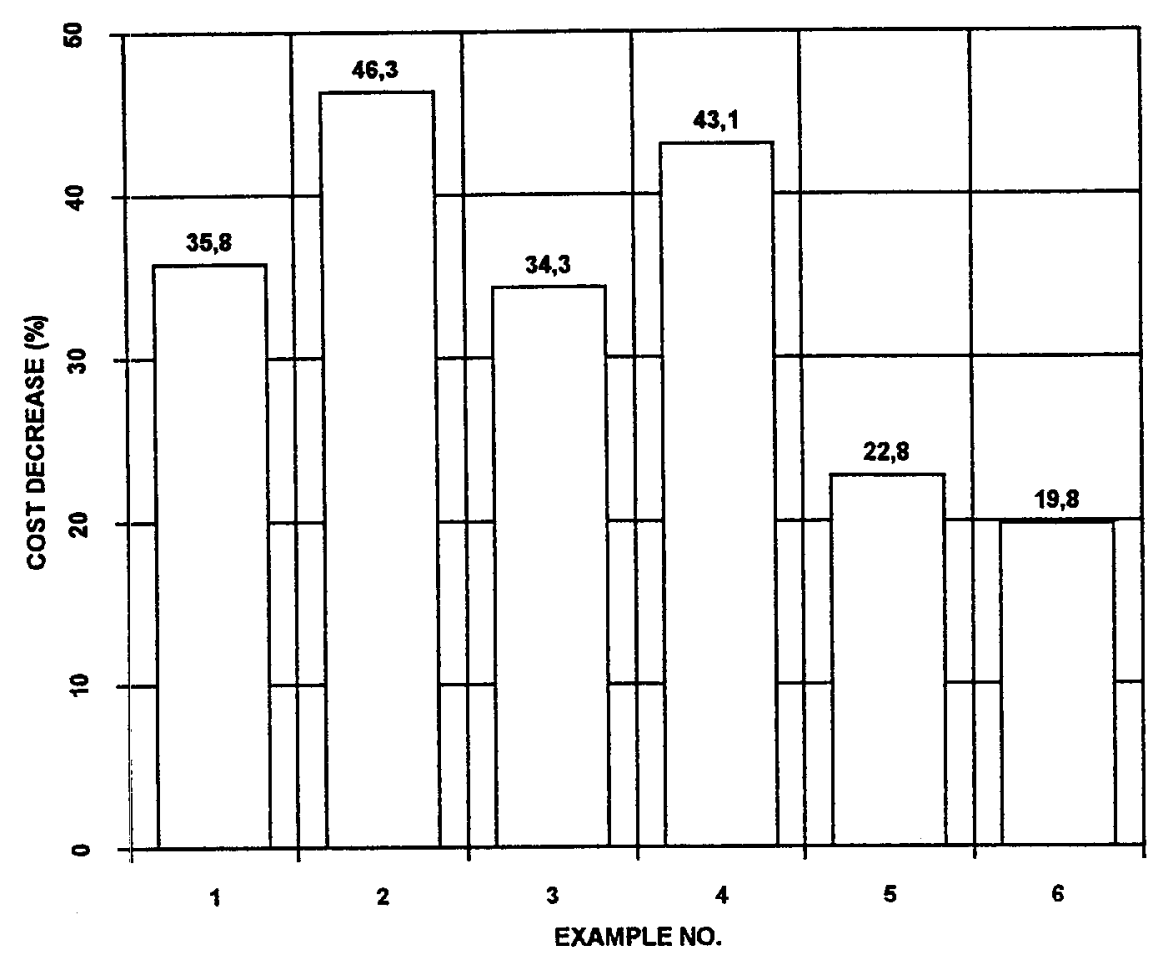

Fig. 12.

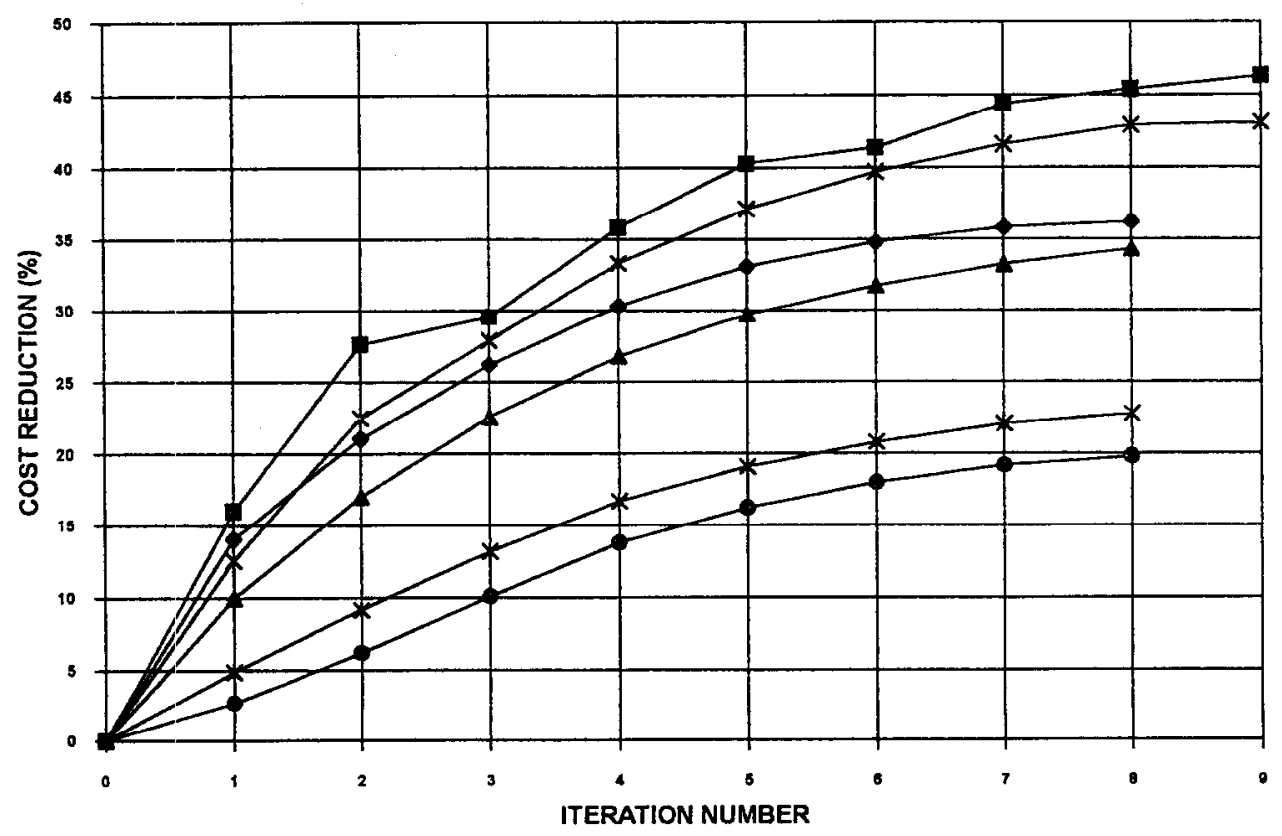

-EXXMPLE $1 \rightarrow-$ EXAMPLE $2-1-$ EXAMPLE $3 \rightarrow-$ EXAMPLE $4 \rightarrow$ EXAMPLE $6-0$-EXAMPLE 0

Fig. 13. 
Table 2. Initial and final (optimized) values of design values

\begin{tabular}{|c|c|c|c|c|c|c|c|}
\hline$X_{i}$ & Initial & Example 1 & Example 2 & Example 3 & Example 4 & Example 5 & Example 6 \\
\hline 1 & 1.500 & 0.9872 & 0.7428 & 1.733 & 1.034 & 1.094 & 1.951 \\
\hline 2 & 1.500 & 2.000 & 1.592 & 2.000 & 1.974 & 2.000 & 2.000 \\
\hline 3 & $0.4000-1$ & $0.2338-1$ & $0.2000-1$ & $0.2000-1$ & $0.2000-1$ & $0.2000-1$ & $0.2000-1$ \\
\hline 4 & $0.4000-1$ & $0.2349-1$ & $0.2354-1$ & $0.2859-1$ & $0.2447-1$ & $0.2373-1$ & $0.3047-1$ \\
\hline 5 & 3.500 & 4.448 & 2.501 & 5.000 & 5.000 & 5.000 & 5.000 \\
\hline 6 & $0.4000-1$ & $0.2000-1$ & $0.2000-1$ & $0.2000-1$ & $0.2000-1$ & $0.2000-1$ & $0.2000-1$ \\
\hline 7 & 1.200 & 0.8569 & 0.9431 & 0.8967 & 0.9710 & 0.9148 & 1.104 \\
\hline 8 & 1.200 & 1.499 & 1.500 & 1.500 & 1.499 & 1.500 & 1.500 \\
\hline 9 & $0.2000-1$ & $0.2138-1$ & $0.2662-1$ & $0.2000-1$ & $0.2000-1$ & $0.2000-1$ & $0.2099-1$ \\
\hline 10 & $0.2000-1$ & $0.3518-1$ & $0.3681-1$ & $0.3713-1$ & $0.3767-1$ & $0.3665-1$ & $0.4012-1$ \\
\hline 11 & 3.000 & 2.256 & 1.972 & 1.384 & 1.811 & 1.824 & 1.613 \\
\hline 12 & $0.2000-1$ & $0.2000-1$ & $0.2000-1$ & $0.2000-1$ & $0.2000-1$ & $0.2000-1$ & $0.2000-1$ \\
\hline 13 & 2.500 & 1.500 & 1.500 & 2.087 & 1.500 & 4.000 & 4.000 \\
\hline 14 & 2.500 & 2.577 & 1.500 & 1.877 & 1.500 & 2.154 & 1.933 \\
\hline 15 & $0.3000-1$ & $0.2000-1$ & $0.2000-1$ & $0.2000-1$ & $0.2000-1$ & $0.2000-1$ & $0.2000-1$ \\
\hline 16 & $0.3000-1$ & $0.2000-1$ & $0.2000-1$ & $0.2003-1$ & $0.2000-1$ & $0.2000-1$ & $0.2000-1$ \\
\hline 17 & 2.500 & 1.500 & 1.500 & 1.500 & 1.500 & 3.412 & 3.405 \\
\hline 18 & 2.500 & 1.500 & 1.500 & 1.500 & 1.500 & 1.500 & 1.500 \\
\hline 19 & $0.2000-1$ & $0.2000-1$ & $0.2000-1$ & $0.2000-1$ & $0.2000-1$ & $0.2000-1$ & $0.2000-1$ \\
\hline 20 & $0.2000-1$ & $0.2000-1$ & $0.2000-1$ & $0.2000-1$ & $0.2000-1$ & $0.2000-1$ & $0.2000-1$ \\
\hline 21 & $0.2500-1$ & $0.1457-1$ & $0.1076-1$ & $0.1605-1$ & $0.1318-1$ & $0.1828-1$ & $0.1608-1$ \\
\hline 22 & $0.2500-1$ & $0.1196-1$ & $0.9685-2$ & $0.1076-1$ & $0.1076-1$ & $0.1076-1$ & $0.1076-1$ \\
\hline 23 & 0.5000 & 0.3000 & 0.3000 & 0.3000 & 0.3000 & 0.3000 & 0.3000 \\
\hline 24 & $0.2000-1$ & $0.2000-1$ & $0.2000-1$ & $0.2000-1$ & $0.2000-1$ & $0.2000-1$ & $0.2000-1$ \\
\hline 25 & 1.000 & 1.076 & 1.076 & 1.083 & 1.071 & 1.423 & 1.475 \\
\hline 26 & $0.2000-1$ & $0.2000-1$ & $0.2000-1$ & $0.2000-1$ & $0.2000-1$ & $0.2000-1$ & $0.2000-1$ \\
\hline 27 & & 12.24 & & 8.610 & & & \\
\hline 28 & & 19.31 & & 37.22 & & & \\
\hline 29 & & 12.97 & & 11.72 & & & \\
\hline 30 & & 21.44 & & 21.44 & & & \\
\hline 31 & & 52.28 & & 52.29 & & & \\
\hline
\end{tabular}

EXAMPLE 2

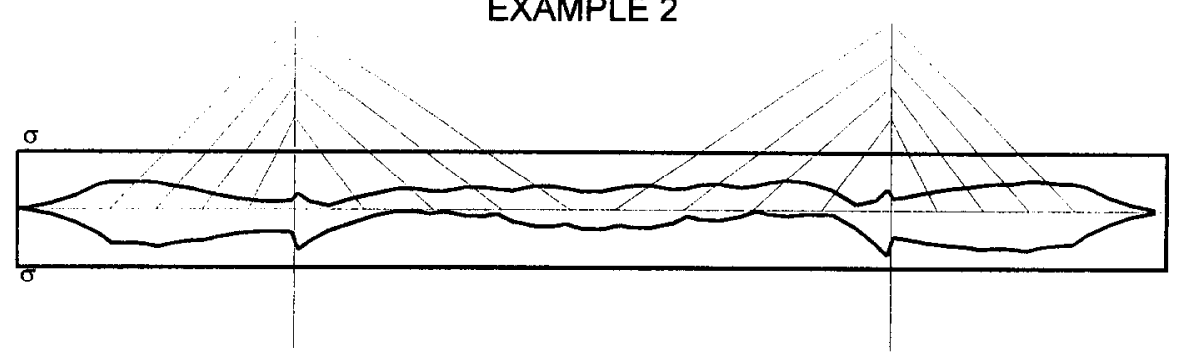

INITIAL UPPER AND BOTTOM MAXIMUM STRESS DISTRIBUTION ON DECK

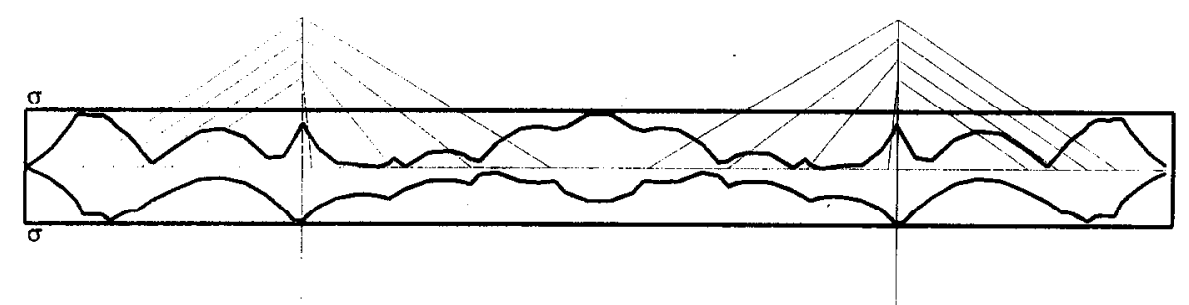

Fig. 14. 
changes and exequible dimensions for the stiffness girder and pylons cross-sections

$$
\begin{gathered}
g_{2}\left(x_{i}\right)=-x_{i} / x_{\mathrm{L}}+1 \leqslant 0 \\
g_{3}\left(x_{i}\right)=x_{i} / x_{\mathrm{U}}-1 \leqslant 0,
\end{gathered}
$$

where $x_{i}$ is the $i$ th sizing variable and $x_{\mathrm{L}}$ and $x_{\mathrm{U}}$ its lower and upper bounds. Similar bounds must be considered for the geometric design variables

$$
\begin{gathered}
g_{4}\left(z_{k}\right)=-z_{k} / z_{\mathrm{L}}+1 \leqslant 0 \\
g_{s}\left(z_{k}\right)=z_{k} / z_{U}-1 \leqslant 0,
\end{gathered}
$$

where $z_{k}$ is the $k$ th geometric variable and $z_{U}, z_{L}$ are its upper and lower bounds, respectively. Additional bounds are set when geometric design variables are considered, to ensure that no geometry violation occurs when these design variables are updated. For example, when design variables of types 4 or 5 (Fig. 1) are to be considered, their total length cannot exceed the side span length. If $i$ and $j$ are the positions of those design variables in $\mathbf{X}$ vector, we write the condition

$$
\left(z_{1}+z_{i}\right) / L_{\mathrm{S}}-1 \leqslant 0,
$$

where $L_{\mathrm{S}}$ stands for side span length.

Additional goals may be established in order to ensure the desired geometric requirements during the optimization process (mesh discretization, ratios of variation of cable spacing on desk and pylons, etc.). For these, the chosen approach was to initially supply all the necessary information, by means of a geometry coefficients set describing such conditions.

The objective is to minimize all of these objectives over sizing and geometry variables $\mathbf{X}$. Different weights can be attributed to different goals just by changing the reference cost, stress or displacement limits. The objective of this Pareto optimization is to obtain an unbiased improvement of the current design. Simões and Templeman [12] have shown that the solution of this multiobjective optimization may be found indirectly by the unconstrained optimization of the convex scalar function

$$
\mathbf{F}(\mathbf{x})=\frac{1}{\rho} \cdot \ln \left[\sum_{j=1}^{M} \mathrm{e}^{\rho(g(\mathbf{x}))}\right]
$$

which is both continuous and differentiable and thus considerably easier to solve.

\subsection{Scalar function optimization}

Problem (5) is unconstrained and differentiable which, in theory, gives a wide choice of possible numerical solution methods. However, since the goal functions $g_{j}(\mathbf{x}, \mathbf{z})$ do not have explicit algebraic form in most cases, the strategy adopted was to solve eqn (5) by means of an iterative sequence of explicit approximation models. An explicit approximation can be formulated by taking Taylor serics cxpansions of all the goal functions $g_{j}(\mathbf{x}, \mathbf{z})$ truncated after the linear term. This gives

$$
\operatorname{Min} \mathbf{F}(\mathbf{x})=\frac{1}{\rho} \cdot \ln \left[\sum_{j=1}^{M} \mathrm{e}^{\left.\rho\left(g_{0}(\mathbf{x})+\sum_{i=1}^{N} \frac{\hat{i} g_{0 i}(\mathbf{x})}{i x_{i}} \mathrm{~d} \mathrm{x}_{i}\right)\right]},\right.
$$

where $N$ and $M$ are, respectively, the number of sizing plus geometric design variables and the number of goal functions. $g_{0 j}$ and $\partial g_{0 j} / \partial x_{i}$ are the goals and their derivatives evaluated for the current design variable vector $\left(\mathbf{x}_{0}, \mathbf{z}_{0}\right)$, at which the Taylor series expansion is made. Problem (6) is an approximation to problem (5) if the values of all the $g_{0 j}$ and $\partial g_{0 j} / \partial x_{i}$ are known numerically. Given such values, problem (6) can be solved directly by any standard unconstrained optimization method.

Solving eqn (6) for particular numerical values of $g_{0 j}$ forms only one iteration of the complete solution of problem (5). The solution vector $\left(\mathbf{x}_{1}, \mathbf{z}_{1}\right)$ of such an iteration represents a new design which must be analysed and gives new values for $g_{1 j}$ and $\partial g_{1 j} / \partial x_{i}$, to replace those corresponding to $\left(\mathbf{x}_{0}, \mathbf{z}_{0}\right)$ in eqn (6). Iterations continue until changes in the design variables become small. During these iterations the control parameter $\rho$ must not be decreased to ensure that a multiobjective solution is found. In this work, a constant value for $\rho$ of 100 was used.

\section{SENSITIVITY ANALYSIS}

Iterative optimization algorithms need to know the way a change in each design variable will affect the requirements expressed as goals. This is the task of the sensitivity analysis and represents most of the computational effort required for structural optimization. The evolution of the problem depends on a critical way on the accuracy with which these values are computed.

The expressions for the discrete analytic method of sensitivity analysis are obtained by differentiating the equilibrium equations

$$
\mathbf{K u}=\mathbf{P} .
$$

The following expression is obtained:

$$
\frac{\partial \mathbf{K}}{\partial x_{i}} \mathbf{u}+\mathbf{K} \frac{\partial \mathbf{u}}{\partial x_{i}}=\frac{\partial \mathbf{P}}{\partial x_{i}}
$$

which can be rewritten in the form

$$
\mathbf{K} \frac{\partial \mathbf{u}}{\partial x_{i}}=\frac{\partial \mathbf{P}}{\partial x_{i}}-\frac{\partial \mathbf{K}}{\partial x_{i}} \mathbf{u}=\mathbf{Q}_{\mathbf{v}}
$$

where $\mathbf{Q}_{v i}$ is the virtual pseudo-load vector of the system with respect to the $i$ th design variable. 


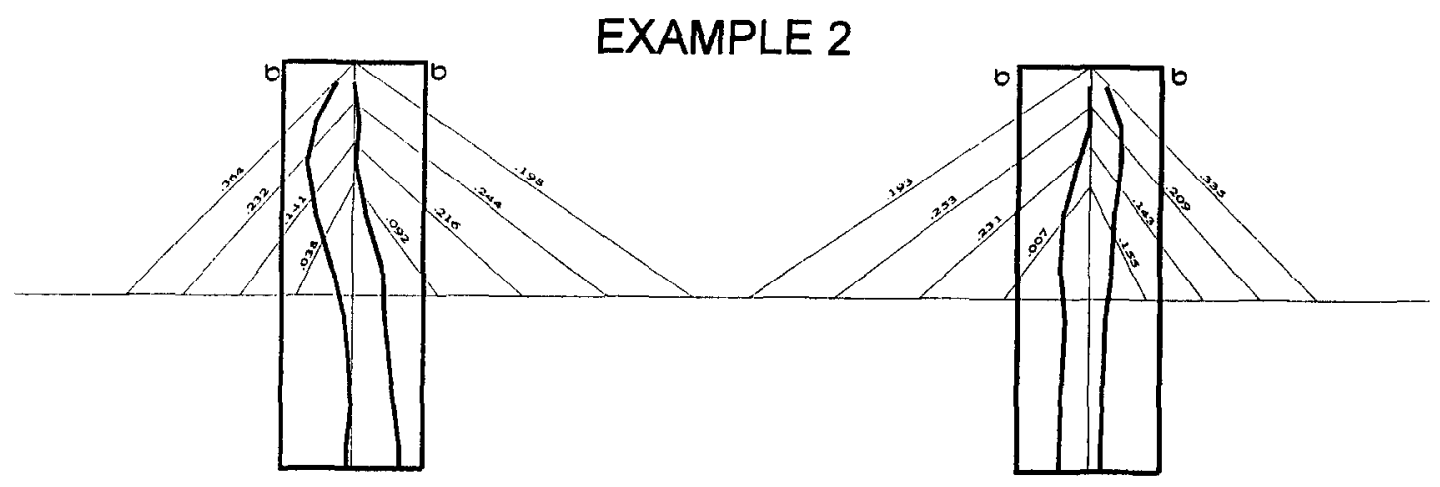

INITIAL MAXIMUM STRESS DISTRIBUTION ON PYLONS AND STAYS

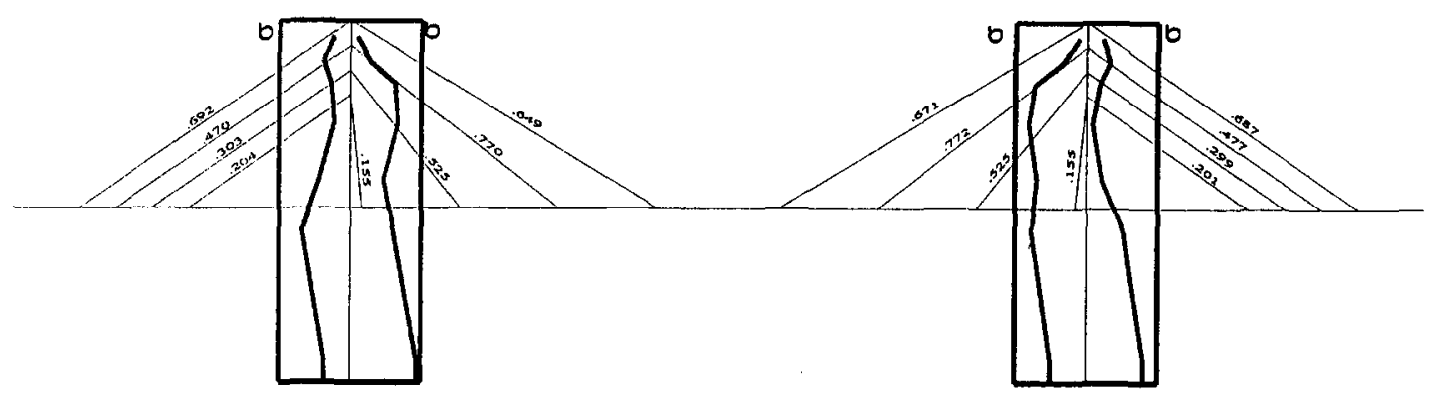

FINAL MAXIMUM STRESS DISTRIBUTION ON PYLONS AND STAYS

Fig. 15 .

The stress derivatives are accurately determined from the chain derivation of the finite element stress matrix

$$
\begin{gathered}
\sigma=\mathbf{D B}_{\mathrm{c}} \mathbf{u}_{\mathrm{e}} \\
\frac{\mathrm{d} \boldsymbol{\sigma}}{\mathrm{d} x_{i}}=\frac{\mathrm{d}\left(\mathbf{D B} \mathbf{B}_{e}\right)}{\mathrm{d} x_{i}} \mathbf{u}_{\mathrm{c}}+\mathbf{D B}_{\mathrm{e}} \frac{\mathrm{d} \mathbf{u}_{\mathrm{e}}}{\mathrm{d} x_{i}}
\end{gathered}
$$

The first term of right-hand side may be directly computed during the computation of element contribution for the global system, on the condition that derivative expressions are pre-programmed and called on that stage. Those values may be recorded in the hard disk and recovered after the current design solution is analysed and the displacement vector $\mathbf{u}$ is obtained.

The second term on the right-hand side is somewhat more difficult to compute because an explicit relation between displacement vector and design variable set does not exist. Pre-programming and storing the stiffness matrix and right-hand side derivatives in the same way as described for the stress matrix, the displacement derivatives may be com- puted by the solution of $N$ pseudo-load right-hand sides. The stress derivatives are then computed in a straightforward way. This process involves the system solution of $N+N P$ right-hand sides (where $N P$ is the number of loading cases), such as in the finite difference method, but it has the advantage that the inversion of the stiffness matrix, which represents most of the computational effort, is done just once.

Regarding the specific kind of structures to be dealt with, the following element sensitivities are now available:

- two-dimensional bar element;

- two-dimensional beam element;

- three-dimensional bar element;

- three-dimensional beam element;

- four-node rectangular plate-membrane element;

- eight-node rectangular plate-membrane element.

\section{EXAMPLES}

Several steel cable-stayed bridge optimization problems have been solved by the proposed method. Six different examples were studied, in each one a 
different combination of design variables set, number of load cases and erection stages being considered, as follows:

example 1 fixed geometry; 1 load case; no erection stages;

example 2 changeable geometry; 1 load case; no erection stages;

example 3 fixed geometry; 3 load cases; no erection stages; example 4 changeable geometry; 3 load cases; no erection stages;

example 5 fixed geometry; 1 load case; 5 erection stages;

example 6 fixed geometry; 3 load cases; 5 erection stages.

Not much emphasis was put on a code of practice criteria because the essential goal was to check the integrated analysis-optimization computer code.
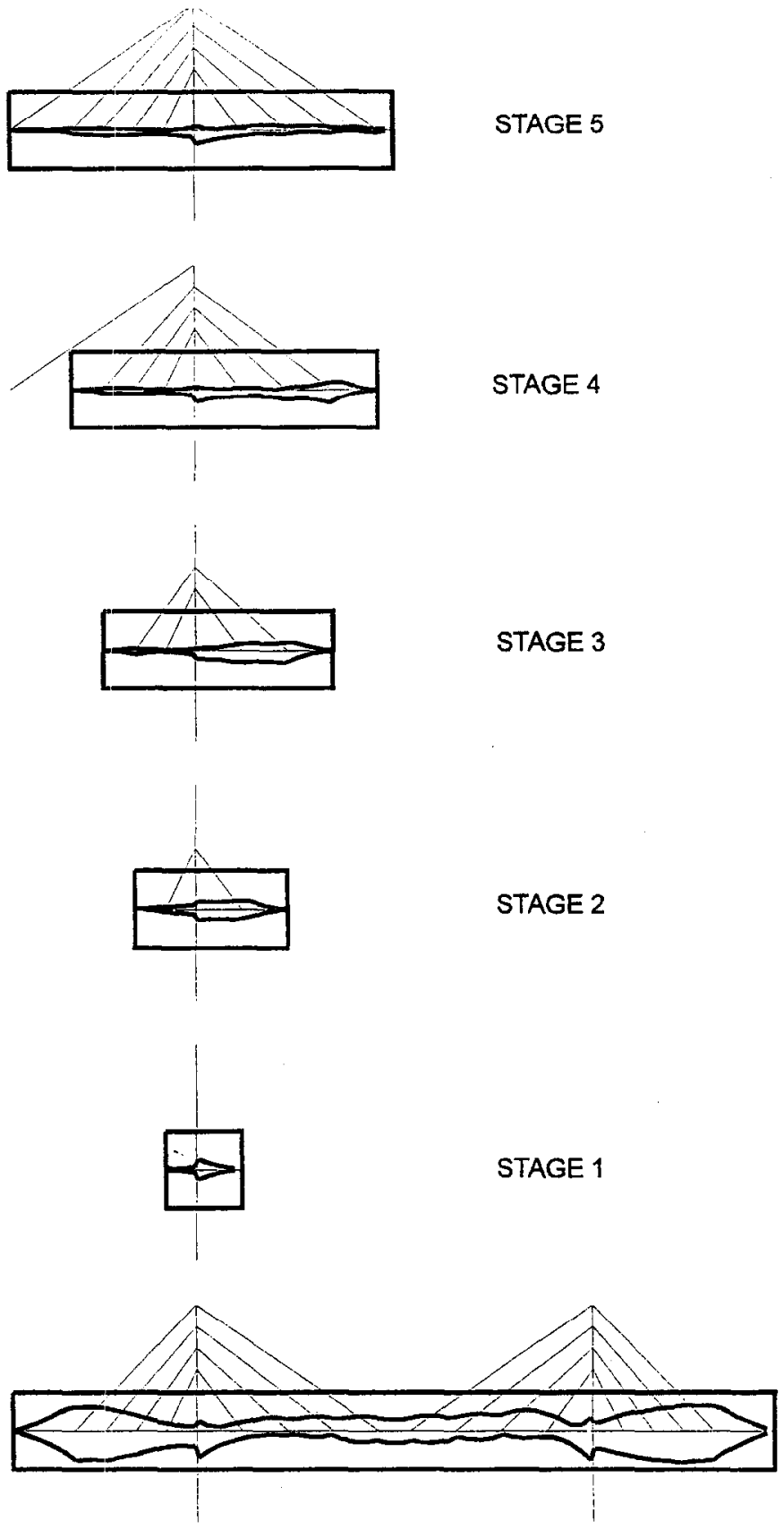

EXAMPLE 6
STAGE 5

STAGE 4

STAGE 3

STAGE 2

\section{STAGE 1}

FINAL STRUCTURE

\section{INITIAL UPPER AND BOTTOM MAXIMUM STRESS DISTRIBUTION ON DECK - FINAL STRUCTURE AND ERECTION STAGES}

Fig. 16. 

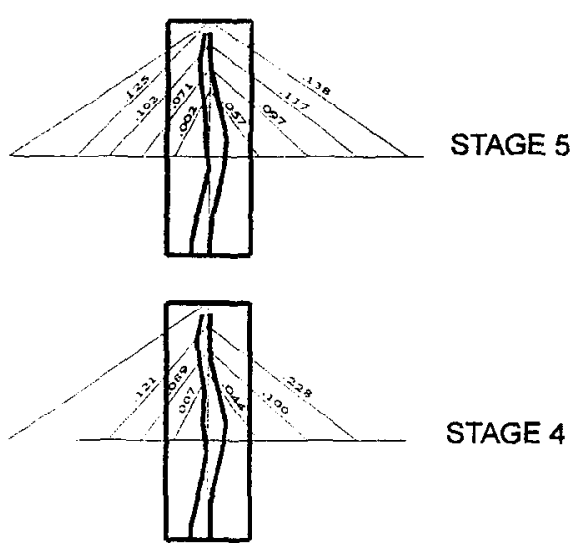

STAGE 4

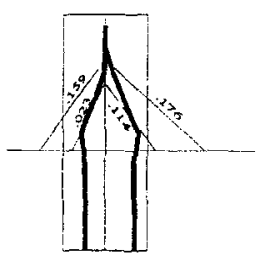

STAGE 3

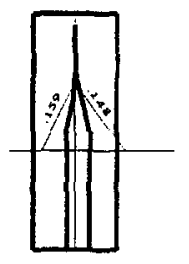

STAGE 2
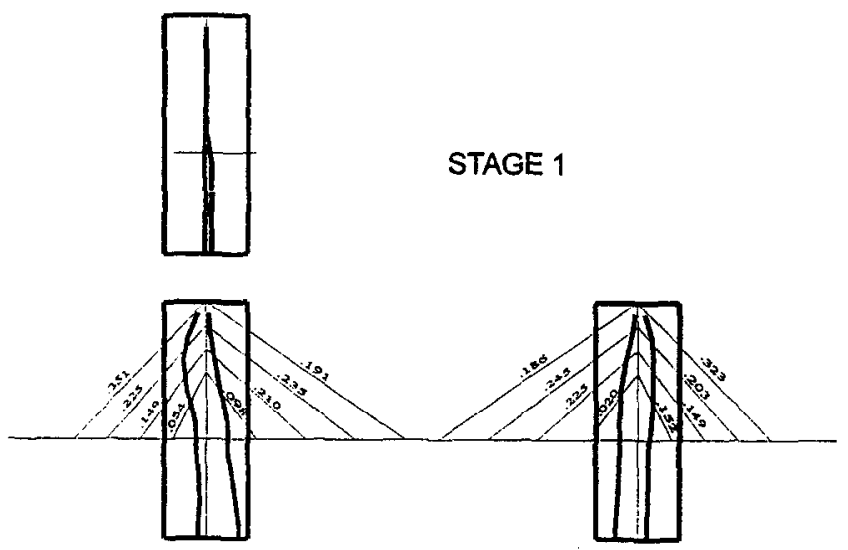

\section{FINAL STRUCTURE}

EXAMPLE 6

INITIAL MAXIMUM STRESS DISTRIBUTION

ON PYLONS AND STAYS - FINAL STRUCTURE AND ERECTION STAGES

Fig. 17.

The geometric description of the initial structure and cross-sections is shown in Figs 8 and 9. The deck was considered to be made of discontinuous folded-plates, simply supported by transverse beams, the deck width being of $20 \mathrm{~m}$. The two side longitudinal beams are asymmetric I shaped, each one being supported by 4 in-plane cables both in the side and central spans. An hollow rectangular section was adopted for the pylons to ensure transverse stiffness.
The criterion for selecting the initial design was to provide a nearly fully stressed design to show the improvement that can be made by using the proposed method. This leads to some oversizing in the examples with one load case only. For the pylons, a moderate oversizing was adopted to reduce the displacements of the midspan and at the top of the pylons.

Structural self-weight, dead and live uniformly 
distributed load and breaking forces were the considered types of load, the three load cases consisting of live load being applied on the whole deck or only on central or side spans, as shown in Fig. 10. A value of $10 \mathrm{kN} \mathrm{m}^{-2}$ was considered for the total uniformly distributed load value, $4 \mathrm{kN} \mathrm{m}^{-2}$ standing for the live load alone. For the erection stages a value of $4 \mathrm{kN} \mathrm{m}^{-2}$ was taken for the erected deck.
For the deck-to-pylon connection, a hinged support was considered on the left pylon, while the right side is simply-supported. The ends of the deck were free to move horizontally. Crosssectional area of all cables was initially assigned the value $0.025 \mathrm{~m}^{2}$. The allowable stresses were set at $200 \mathrm{MPa}$ for deck and pylon elements and $500 \mathrm{MPa}$ for cable elements. All type of structural
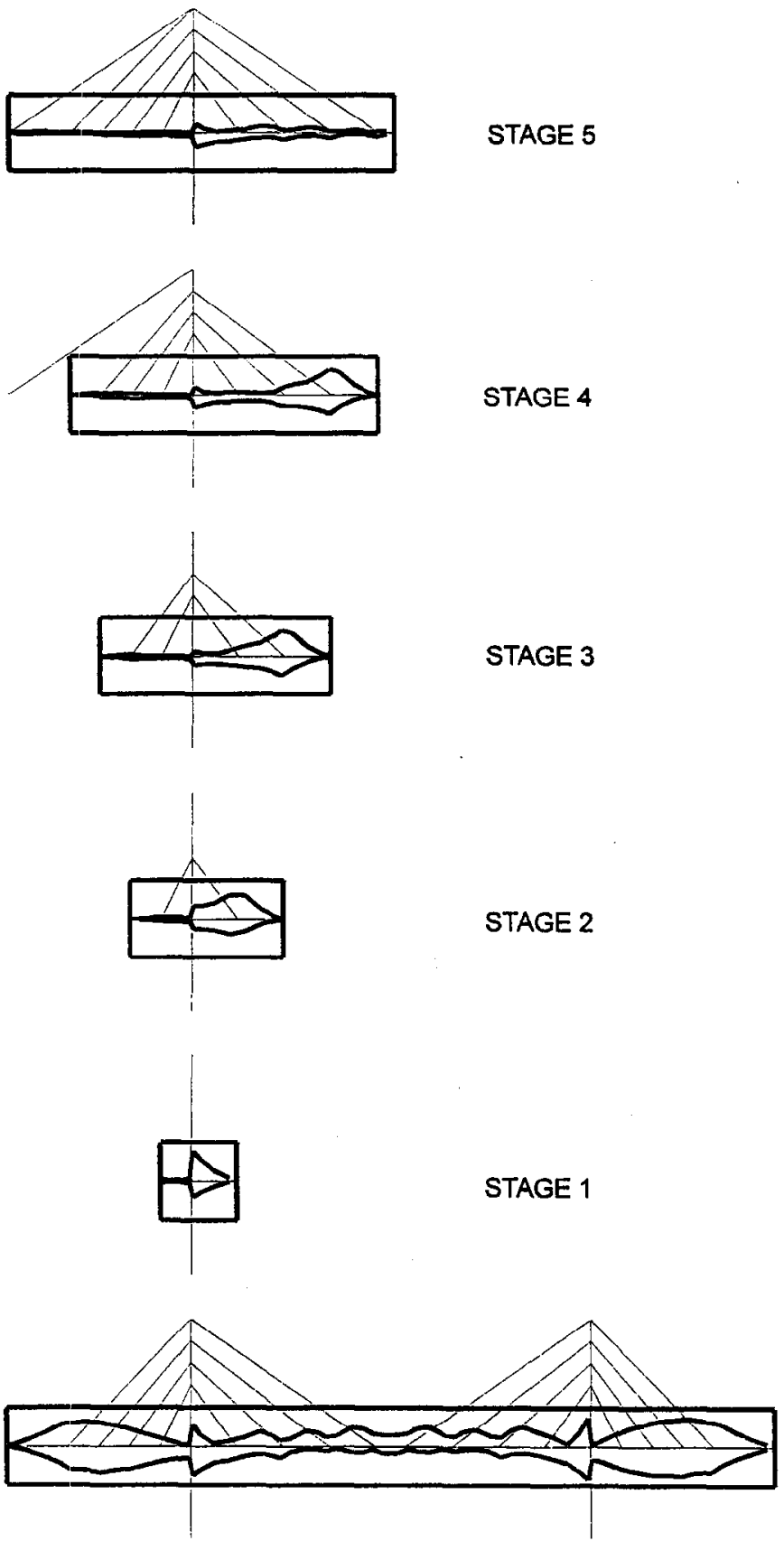

EXAMPLE 6
STAGE 5

STAGE 4

STAGE 3

STAGE 2

\section{FINAL UPPER AND BOTTOM MAXIMUM STRESS DISTRIBUTION} ON DECK - FINAL STRUCTURE AND ERECTION STAGES

Fig. 18. 

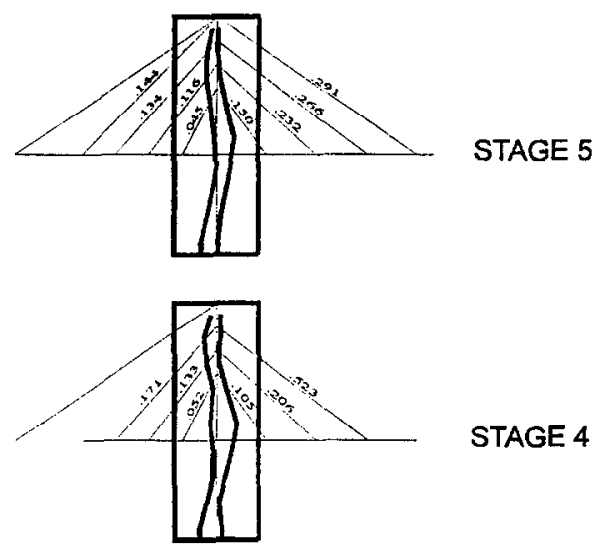

STAGE 4

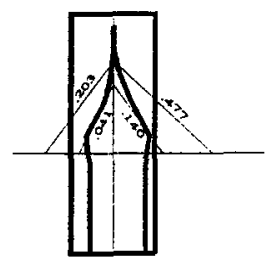

\section{STAGE 3}

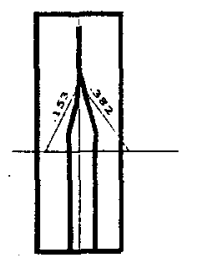

STAGE 2
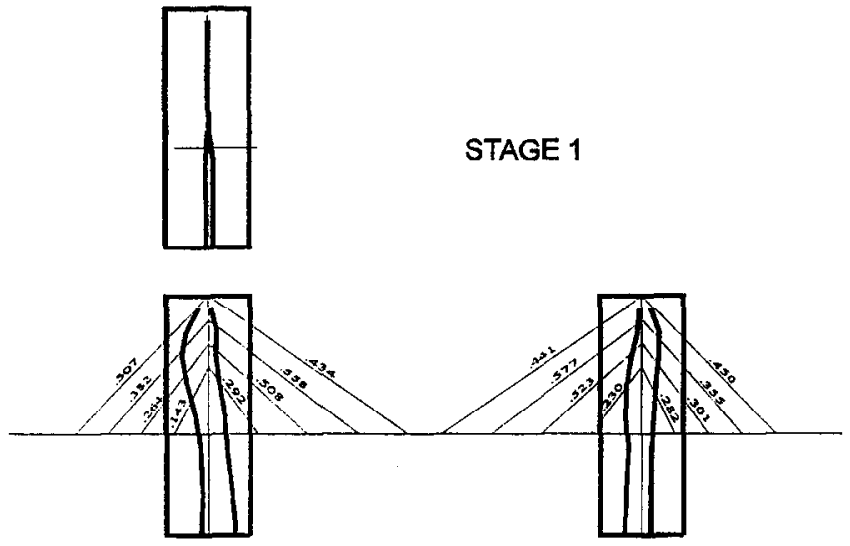

FINAL STRUCTURE

\section{EXAMPLE 6}

FINAL MAXIMUM STRESS DISTRIBUTION

ON PYLONS AND STAYS - FINAL STRUCTURE AND ERECTION STAGES

Fig. 19.

elements were assigned a cost per unit of volume of 1.000 .

The design variable set, its meaning and bounds are listed on Table 1. For examples 1, 3, 5 and 6 only cross-section related design variables were considered $\left(x_{1}-x_{22}\right)$, the additional five geometric design variables being used in examples 2 and 4 .

Erection stages considered on the examples are shown in Fig. 11. At stages 4 and 5, tempor- ary back-staying was considered to reduce the large eccentricity of the resulting deck load with respect to the pylons. Temporary bending continuity between deck and pylon is assumed in stage 1 , a hinged connection being further considered.

The deck slab is supported by transverse beams spaced $5.00 \mathrm{~m}$ apart, which are in turn supported by the side girders.

When geometric design variables are considered, 
remeshing must be done at the end of each optimization cycle because of the corresponding geometry changes. This remeshing ranges from a nodal co-ordinates adjustment under fixed discretization to a complete node and element regeneration, as in examples 2 and 4 . In fact, the fixed positions of the transverse beams may require additional nodes and elements to be generated to fit the initially prescribed discretization.

Convergence is set on the basis of the cost decrease in one iteration becoming smaller than $1 \%$ of the previous cost. In Fig. 12 the final cost reduction for each example is plotted, while in Fig. 13 the progression of the cost reduction towards the optimum can be seen. The introduction of geometric design variables produces a remarkable solution improvement. The consequences of considering the erection stages are strongly dependant on the construction sequence and temporary structural devices, such as those mentioned above. For instance, if temporary staying had been provided earlier in stage 3 instead of stage 4 , that erection stage would not have been critical for the pylons cross-sections. This can be observed in Table 2, where the bottom pylons cross-section optimized height increases from the lower to the upper bound when erection stages are included.
The initial and optimized values of the design variable are written in Table 2, bold standing for upper bounds while lower bounds are assigned italic typing. Concerning the deck, it can be seen that when no geometry change is allowed, the side span beams cross-section height equals the upper bound because of the large downside reaction at the end supports, in particular with the live loading acting on the central span only. Moving the outer cables to a closer position from the ends greatly reduces the bending stresses, allowing for a smaller cross-section height, as the results of example 2 shows. A trend to pylon height decrease is detected, which seems somewhat unexpected because it reduces the cables efficiency and increases the normal force in the deck. The effect of the erection stages may be seen in the drastic change of the lower pylon cross-section height, as was referred before. The wave pattern of the final stress diagrams of Figs 14-19 shows the reduction of the relative deck/cables stiffness, indicating that the beam in the initial design is much more self-supporting that in the optimum. These figures represent the maximum stress distribution for initial and optimized designs of examples 2 and 6.

The cables remain under moderate stresses because the same cross-section was assigned to all the side cables, and the same for the central cables, so the

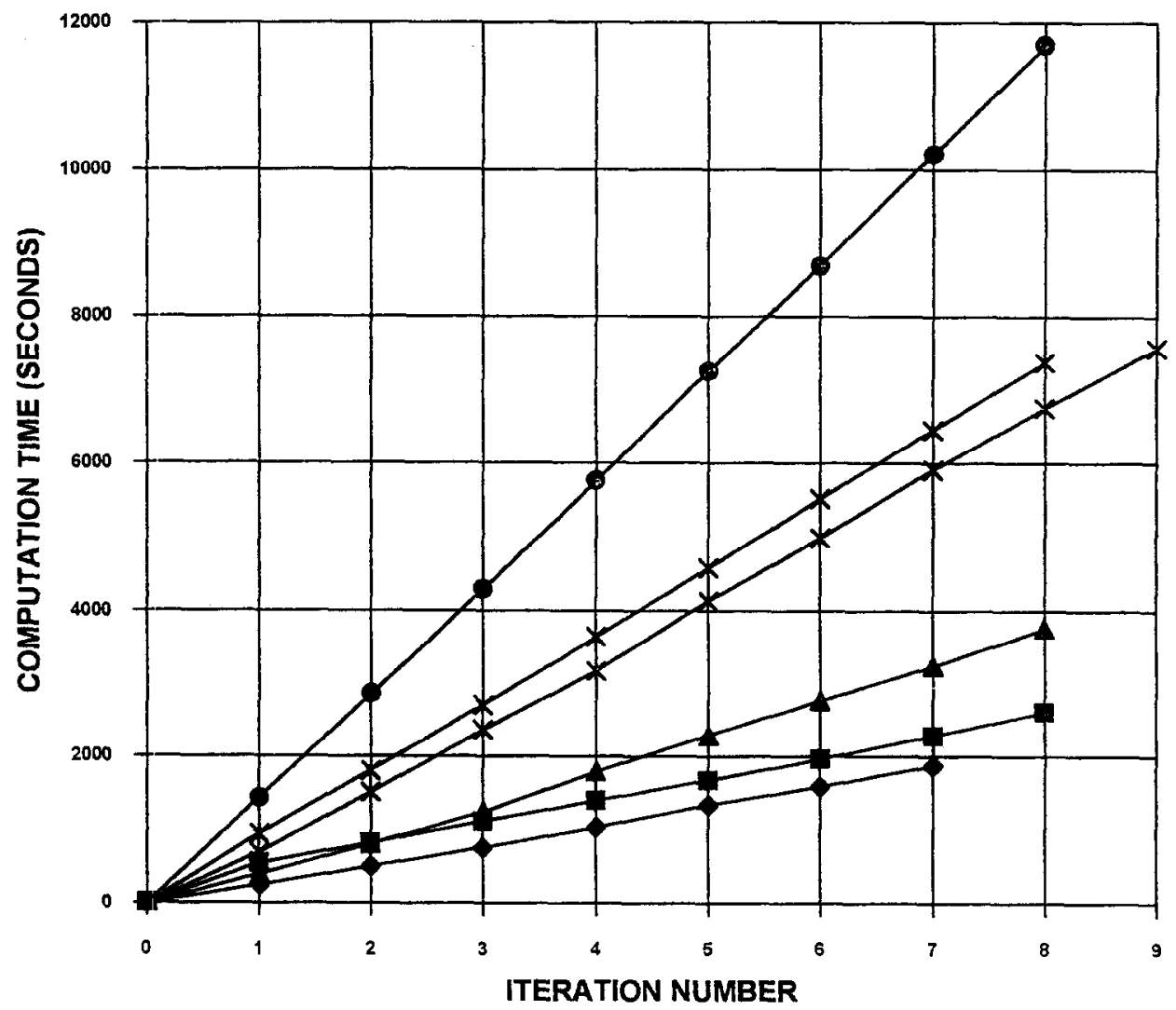

EXAMPLE 1 - EXAMPLE $2-4$ EXAMPLE $3 \rightarrow$ EXAMPLE 4 - 6 EXAMPLE 5 - EXAMPLE 6

Fig. 20. 
result is conditioned by the most tensioned one. Furthermore, its small contribution for the global volume and the low cost factor reduces their influence on the scalar global objective function and, so, their priority.

Comparison between predicted stresses at the end of each iteration and those computed for the updated structure showed maximum differences of about $1 \%$, which shows that first-order sensitivity analysis is accurate enough for dealing with these problems, provided that moderate move limits are imposed on the optimization process. However, some unstable behaviour may arise when complete remeshing is required, because the evaluation points for stresses and sensitivities change from one iteration to another. This effect may be reduced by a closer discretization near the critical points which we know to occur at the cable anchorages, midspan and supports. Move limits of $10 \%$ of the current design values were considered in the examples.

Figure 20 plots the processing time spent until convergence against the number of objectives (stresses), for each example.

\section{DISCUSSION AND CONCLUSIONS}

This paper has shown that the optimization of cable-stayed bridges can be carried out efficiently by the proposed design method consisting of the combination of two programs: a finite element analysis code and an optimization module. The sensitivity analysis is based on the analytic derivation of the response functions and provides the link between these two.

The minimax formulation adopted here allows the simultaneous optimization and control of many different engineering goals. Pareto solutions were obtained efficiently for the multi-objective problem through the scalar minimization of a nonlinear convex function.

The examples solved in the course of this work provided considerable insight into the behaviour of cable-stayed bridges. The total cost of the steel cable bridge is affected by the cable anchor positions on the main girder and pylon. Stresses due to the erection sequence change the optimum solution also and must be considered. Hence, the treatment of the cable anchor positions and the height of the pylon as design variables and the consideration of the stresses arising during construction are extremely significant.

A compromise between a general- and specificpurpose program was sought by implementing, at the code level, the concept of design variable types, some of them common to a wide class of structures and some specific. The implicit part of the sensitivity analysis being independent of the design variable type, new kinds of problems or structures may be analysed by simply adding the specific design variable types code to the element routines.
The software used for running the examples of the present paper is a PC platform-based finite element package running under DOS with Phar Lap's DOS Extender, which allows for structural analysis and optimization of problems requiring up to 16 Mbytes of memory. The original finite element core was the VAX/VMS based MODULEF package, to which the first author is adding and developing the sensitivity analysis, interface and specific optimization code. The option for this platform was the wide use, portability and autonomy for the user, in addition to the existence of a great number of popular and affordable software tools for helping the post-processing task. In that context, an interface to AutoCad was developed, from where the graphical data may be exported to other applications.

Finally, this work has only touched the surface of optimizing the design of cable-stayed bridges. Nevertheless it has shown that there are potential savings to be made through the use of optimization. This algorithm can also be used with more complex structural modelling, namely the formulation of more complex constitutive laws (concrete stress-strain relationship, creep, etc.) as well different types of loading (dynamic and/or thermal effects, etc.).

Acknowledgement-The authors wish to thank the financial support given by JNICT (junta Nacional de Investigação Científica e Tecnológica, Projecto STRDA/C/TPR/576/92).

\section{REFERENCES}

1. MODULEF Reference Guide. INRIA (1992).

2. N. Gimsing, Cable Supported Bridges-Concept and Design. Wiley-Interscience, Chichester (1983).

3. W. Podolny, J. B. Scalzy, Construction and Design of Cable-Stayed Bridges. Wiley-Interscience, New York (1986).

4. R. Walther, B. Houriet, W. Inler and P. Moia, Cable-Stayed Bridges. Telford, London (1988).

5. S. Ohkubo and K. Taniwaki, Shape and sizing optimization of cable-stayed bridges. In Optimization of Structural Systems and Industrial Applications (Edited by $S$. Hernandez and C. A. Brebbia), pp. 529-540. Elsevier Applied Science, London (1991).

6. L. M. C. Simões, J. H. O. Negrão, Sizing and geometry optimization of cables stayed bridges. Comput. Struct. 52, 309-321 (1994).

7. R. T. Haftka and H. M. Adelman, Recent developments in structural sensitivity analysis. Struct. Optim. 1, 137-151 (1989).

8. W. Kanok-Nukulchai and G. Hong, Nonlinear modelling of cable-stayed bridges. J. Construct. Steel Res. 26 (1993).

9. A. S. Nazmy and A. M. Abdel-Ghaffar, Three-dimensional nonlinear static analysis of cable-stayed bridges. Comput. Struct. 34, 257-271 (1990).

10. C. K. Choi and I. H. Choi, An expert system for selecting types of bridges. Comput. Struct. 48, 183-192 (1993).

11. Z. Behin and D. W. Murray, A substructure-frontal technique for cantilever erection and analysis of cable-stayed bridges. Comput. Struct. 42, 145-157 (1992).

12. L. M. C. Simões and A. B. Templeman, Entropy-based synthesis of pretensioned cable net structures. Engng Optim. 15, 121-140 (1989). 